\title{
The impact of environmental regulation on environmental performance: A focus on third party logistics service providers in an emerging country
}

\author{
Quang-Huy Ngo ${ }^{a^{*}}$
}

\begin{tabular}{|c|}
\hline CHR O N I L L \\
\hline $\begin{array}{l}\text { Article history: } \\
\text { Received March 12, } 2021 \\
\text { Received in revised format May 7, } \\
2021 \\
\text { Accepted August } 22021 \\
\text { Available online } \\
\text { August } 62021\end{array}$ \\
\hline $\begin{array}{l}\text { Keywords: } \\
\text { Environmental performance } \\
\text { Environmental regulation } \\
\text { Environmental strategy } \\
\text { Third-party logistics } \\
\text { Vietnam }\end{array}$ \\
\hline
\end{tabular}

\section{Introduction}

Nowadays, the business theme is different from the past. In the past, most of the arguments when doing business is due to profit. In this regard, much literature in business focuses on drivers of economic performance. However, focusing too much on economic performance may lead to the damage of the natural environment. As a result, the modern literature raises a concern: organizations should not only focus on economic performance but also environmental performance (EP). From the government's perspective, EP can be enhanced by implementing environmental policy as command-and-control environmental regulation (CAC_ENV_REG). The literature reveals that the implementation of this regulation directly discourages the polluting behavior of organizations (Zhang, Wang, Xue, \& Yang, 2018). It can be explained by using the institutional theory. According to institutional theory, this regulation exerts coercive pressure, forcing organizations to comply (see Powell \& DiMaggio, 2012). In this regard, it may interpret that the implementation of this regulation may directly improve EP. From an organizational perspective, businesses can find an EP by aligning their strategy with CAC_ENV_REG. Particularly, the conventional knowledge in strategic management suggests that CAC_ENV_REG is the driver of environmental strategy (ES) (Henriques \& Sadorsky, 1996). Moreover, the pursuit of this strategy is expected to improve EP (Latan, Jabbour, de Sousa Jabbour, Wamba, \& Shahbaz, 2018; Solovida \& Latan, 2017). In this regard, the ES may impact the link between CAC_ENV_REG and EP. This proposal can be based on the contingency theory. Accordingly, this theory posits that the alignment between external pressure as environmental regulation and ES improves EP. However, this study addresses three gaps. First, up until now, many prior studies focus on the impact of ES and economic performance. The role of this strategy on EP seems to be ignored (Kraus, Rehman, \& García, 2020). As a result, there is limited knowledge on

* Corresponding author

E-mail address: huynq121@,fe.edu.vn (Q.-H. Ngo)

(C) 2021 Growing Science Ltd. All rights reserved.

doi: $10.5267 /$ j.uscm.2021.8.003 \begin{abstract}
A B S T R A C T The literature addresses the link between command and control environmental regulation and
environmental performance. However, there is a lack of attention paid to how environmental strategy plays a mediating role in this relationship. In addition, the environmental research in the theoretical lens of institutional theory and contingency theory, this study examines the mediating role of environmental strategy on the relationship command and control environmental regulation
and environmental performance. Data were collected from small and medium enterprises operating in the logistics industry of Vietnam and partial least square structural equation modeling was environmental strategy on the link between command and control environmental regulation and environmental performance. In this regard, this study contributes to growing empirical evidence through mediators. Besides, this study also extends the current knowledge of environmental strategy pursued by third-party logistics providers.
\end{abstract}


whether or not the alignment between CAC_ENV_REG and ES allows the implication of EP. Furthermore, although increasing attention has been paid to the adoption of environmental management practices of third-party logistics service providers (3PLSPs), there is a lack of focus on the ES of these providers (see Evangelista, Santoro, \& Thomas, 2018). ES and EP are particularly relevant and crucial for these providers (Laguir, Stekelorum, \& El Baz, 2020). As a result, it hinders the extension of the current knowledge on this strategy of 3PLSPs. Finally, the environmental issue is becoming a global trend. There are many pieces of research focused on emerging countries. However, empirical evidence from Vietnam is scarce. The Vietnamese government has implemented environmental regulations recently. There is no study addressing the consequences of this implementation. It limits the practical implications relating to the impact of the implementation of environmental regulation. Acknowledging these gaps, this study aims to address how 3PLSPs pursue ES deals with the CAC_ENV_REG to improve EP. Drawing from the contingency theory and institutional theory, this study proposes that the alignment between CAC_ENV_REG and ES allows the implication of EP. This study uses data collected from 175 3PLSPs operating in Vietnam to examine the research model. The results reveal that the alignment allows 3PLSPs to enhance EP through the pursuit of ES. In the light of findings, this study contributes to the literature twofold. First, the results of past studies indicate that environmental regulation, directly and indirectly, influences EP (see Graafland \& Bovenberg, 2020; Guerci, Longoni, \& Luzzini, 2016; Jin, Du, Long, \& Boamah, 2019; Wu, Yang, \& Zhou, 2020). Because mediators influence the indirect effect, the search for the mediator is crucial for shedding light on a question which is what conditions allow CAC_ENV_REG to have a positive impact on EP. This study shows the mediating role of ES on the link between CAC_ENV_REG and $\overline{E P}$ in an emerging context. In this regard, this study contributes to the literature by addressing the role of ES on the relationship between CAC_ENV_REG and EP. Second, research on environmental management and research on the antecedents and consequences of ES are well documented. However, there is little attention paid to the context of 3PLSPs. In another context, environmental regulation is one of the crucial factors determining the pursuit of ES (Yu, Ramanathan, \& Nath, 2017), it is still questioned that this result is relevant to 3PLSPs. In this regard, it challenges the generalization of the prior study's results in the 3PLSPs contexts. This study addresses this challenge by showing that 3PLSPs pursue ES due to environmental regulation and find EP implications. In this regard, this study contributes to the literature by shedding light on the antecedents and consequences of 3PLSPs's ES.

This study's outline is as follows. The subsequent section presents the theoretical concepts of the variables and the relationship between them. After that, the methodological section is provided. The result section follows next. The fifth section is the discussion. The last section concludes and reveals the limitations and directions for future research.

\section{Theoretical concept and hypothesis developments}

\subsection{Theoretical concept}

\section{Command-and-control environmental regulation}

Environmental regulation refers to the governmental policies relating to the environment, which aims to mitigate the negative impact of the business organization on the natural environment, and results in a context where business organizations will actively exert environmentally friendly behaviors (Eiadat, Kelly, Roche, \& Eyadat, 2008). As a result, it refers to the governmental tools to protect and improve environmental conditions (Liao \& Tsai, 2019). It is a convenient tool, which the government uses to solve environmental issues (Wang, Zhang, \& Zeng, 2016). This study focuses on CAC_ENV_REG because this regulation is commonly used in emerging countries (Requate, 2005). This environmental regulation discourages organizations from contaminating the environment by using laws, regulations, and policies, which directly affect the polluting organizations (Zhang et al., 2018).

\section{Environmental strategy}

ES refers to the set of organizational initiatives to serve the purpose of environmental protection by establishing action plans to reduce the harmful impacts of the operational activities on the natural environment (Bansal \& Roth, 2000). This strategy can be varied in degree between reactive, focused, opportunities, and proactive (Lee \& Rhee, 2007). Organizations pursuing the first type of this strategy are more likely to ignore the harmful impact of their operation on the environment. As a result, it was shown that this type of ES has a lower score in terms of EP than other types (Kim, 2018). Organizations pursuing the second type of ES are due to the compliance of environmental regulation (Do, Nguyen, Nguyen, \& Johnson, 2019). In this regard, these organizations consider a limited number of environmental criteria when they formulate their strategy because they aim to minimize risk, liabilities, and costs (Lee \& Rhee, 2007; Roome, 1992). Opportunistic types of ES permit a higher degree of environmental concern than the focused type (Lee \& Rhee, 2007). Although organizations pursuing this strategy consider several environmental criteria in their strategic formulation, they are less likely to commit to those environmental issues (Do et al., 2019). Lastly, the proactive type of ES is no longer driven by the pressure to implement environmental regulation. Instead, organizations pursuing it are more likely to aim to improve pollution control, green entrepreneurship, and reputation building (Eisenhardt \& Martin, 2000) and find competitive advantages (Delmas, Hoffmann, \& Kuss, 2011). 
Institutional theory may provide some insight into how organizations may imply environmental management practices due to the pressure resulting from environmental regulation. According to institutional theory, organizations can secure their positions and legitimacy only if they confirm the broader external factors such as laws, regulations, culture, norms, values, and social expectations, which are referred to as institutions (Meyer, Rowan, Powell, \& DiMaggio, 1991; Scott, 2013). Thus, institutional factors pressurize organizations to act according to and affect organizational, managerial decisions (DiMaggio \& Powell, 1983).

\section{Contingency theory}

The contingency theory provides a theoretical lens to explain how the alignment between external environment and internal characteristics of the organization leads to the performance implication. Prior studies borrow this theory to explain the performance implications of small businesses (see Ngo, 2021b, 2021c) and public organizations (see Ngo, 2020). Beside, this theory was also adopted to explain the effectiveness of strategic alignment (see Ngo, 2021a). According to the theory, when there is an alignment between strategic pursuit and external environment, there is performance implication (Venkatraman \& Prescott, 1990). In this regard, the alignment between command-and-control regulation and ES permits the implication of EP.

$\mathrm{H}_{4}$

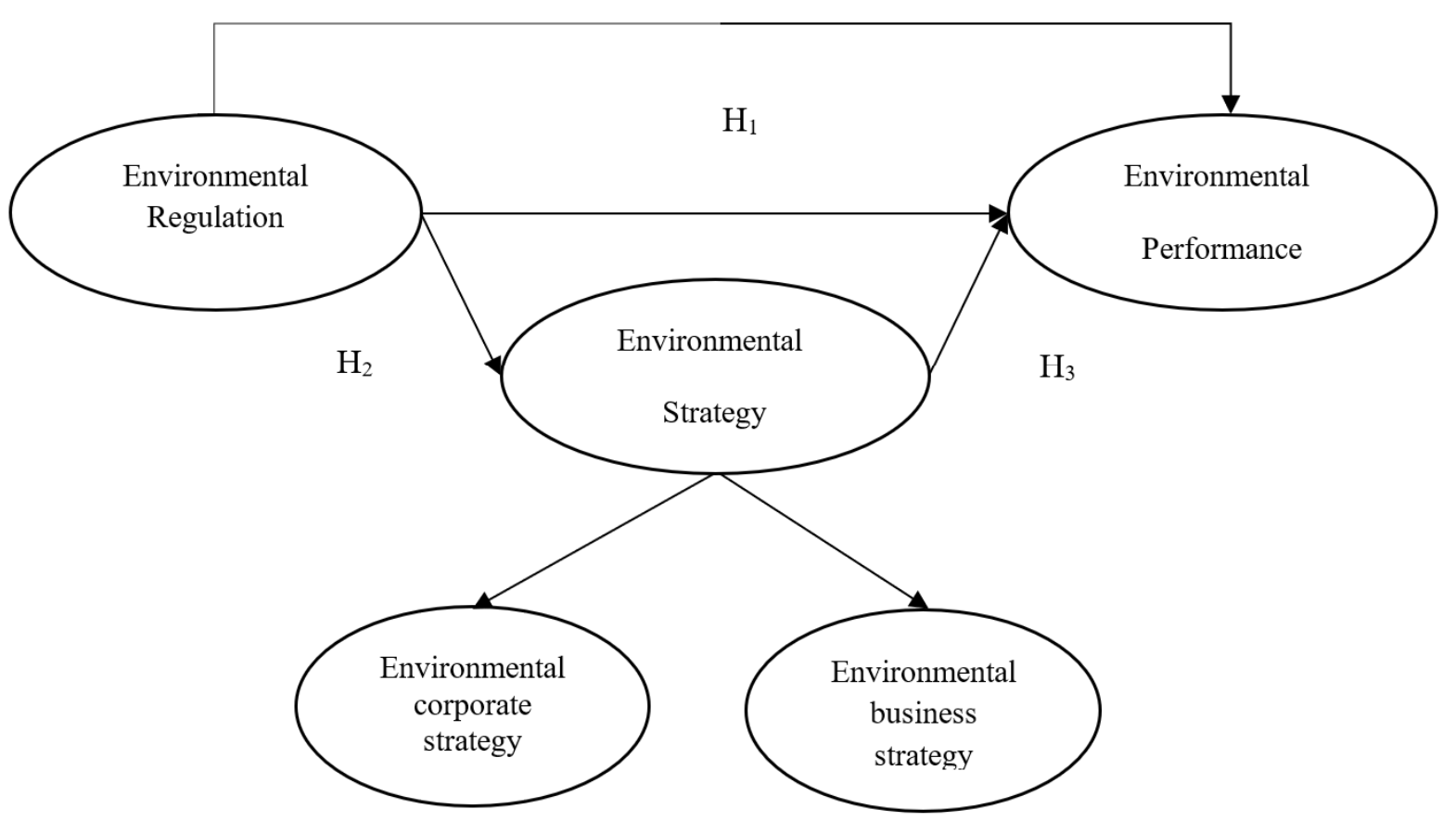

Fig. 1. Proposed research model

\subsection{Hypothesis developments}

The link between $C A C_{-} E N V \_R E G$ and $E P$

The environmental literature well documents the positive impact of environmental regulation on EP. This positive association can be explained through the theoretical lenses of institutional theory. Accordingly, the isomorphism mechanism continuously creates pressure to shape organizations, and therefore, organizations must comply with the norms and practices of the operating environment to gain legitimacy (Meyer et al., 1991; Scott, 2013). In institutional theory, an asymmetry of power leads to coercive pressures because it forces organizations to comply with a specific behavior through legal sanction (Meyer \& Rowan, 1977). A CAC_ENV_REG can refer to coercive pressure because this regulation aims to force organizations to comply with environmental regulation (Li \& Ramanathan, 2018). In this regard, organizations may adopt environmental practices to maintain their legitimacy. Although institutional theory does not predict the direct relationship between environmental regulation and EP, prior empirical evidence confirms the direct relationship. First, Graafland and Bovenberg (2020) found a significant positive relationship between government regulation and EP. Second, Wu et al. (2020) indicated a direct positive relationship between environmental regulation and environmental productivity. In the same vein, this study 
expects the same effects: a CAC_ENV_REG improves the environmental regulation of 3PLSPs. The first hypothesis is as follows.

\section{H1. There is a positive association between $C A C_{-} E N V \_R E G$ and EP.}

\section{The link between $C A C_{-} E N V_{-} R E G$ and $E S$}

Environmental regulation is the most crucial source, which encourages ES (Henriques \& Sadorsky, 1996). Environmental regulation influences organizational strategy because the organization must consider the impact of this regulation on this strategy (Rugman \& Verbeke, 1998). It is suggested that when organizations actively follow these regulations, they enjoy the benefit of being the first-mover, which allows the competitive advantages because they satisfy a high demand for environmentally friendly products/services (Porter \& Van der Linde, 1995). As a result, environmental regulation influences organizational strategy relating to environments. Environmental regulation may have an impact on ES. Such regulations, including compulsory laws, rules, and policies are developed to protect the environment (López-Gamero, Molina-Azorín, \& Claver-Cortés, 2009). According to institutional theory, this regulation exerts a controlling force on organizations, which coercively follows the environmental rules and laws (see Powell \& DiMaggio, 2012). As a result, organizations comply with such regulations to avoid the legal risk (e.g., close monitoring of government entities) and legal coercion (e.g., tighter enforcement of current regulations) (Berrone, Fosfuri, Gelabert, \& Gomez-Mejia, 2013). Thus, it is expected that CAC_ENV_REG strongly induces ES because the pressure encourages organizations to comply and, in turn, follows ES. It leads to the first hypothesis as follows.

\section{$\mathbf{H}_{2}$ : There is a positive association between CAC ENV REG and ES.}

\section{The link between ES and EP}

Recently, business strategy was a crucial determinant of environmental protection (Kong, Yang, Liu, \& Yang, 2020). Zhou, Shu, Jiang, and Gao (2019) emphasized the crucial role of ES on environmental issues and advised researchers to focus on this strategy due to its benefits to the environment. Prior studies reveal that pursuing ES improves EP (see Kraus et al., 2020; Latan et al., 2018; Solovida \& Latan, 2017). The positive relationship between ES and EP can be explained as follows. EP can be improved by setting environmental goals and objectives (see Eagan \& Joeres, 1997). These goals and objectives allow measuring the impact of their operation on the environment. The ES emphasizes these environmental goals and objectives, and in turn, pursuing this strategy improves EP by reducing the harmful impact of operational activities on the environment (see Jaeckel, 2020). With this regard, it is expected a positive association between ES and EP. Therefore, the fourth hypothesis is proposed as follows.

\section{$\mathbf{H}_{3}$ : There is a positive association between ES and EP.}

\section{The effectiveness of the alignment between CAC_ENV_REG and ES}

The contingency theory predicts that when organizations find the alignment between the external environment and their strategic pursuit, they can gain the performance implication thanks to the effectiveness of this alignment. To examine the alignment, Venkatraman and Prescott (1990) proposed an assessing framework, which requires the strategic pursuit to mediate the link between external environment and performance. Based on this framework, this study proposes that ES acts as the mediator between CAC_ENV_REG and EP. It leads to the last hypothesis proposed as follows.

\section{H4: There is a mediating effect of ES on the link CAC ENV REG and EP.}

\section{Methods}

This study uses survey methods to examine the research model. One reason is that because there are no available data measuring three variables in the model, it is adequate to use this method. It is similar to other studies in the context of 3PLSPs. This study analyzes data by using partial least square structural equation modeling (PLS-SEM). First, SEM allows this study to establish the relationship between observed items and latent variables. Second, PLS-SEM permits the analysis of the causeeffect relationship between latent variables in the model. In the PLS-SEM analysis, there are two stages: evaluation of measurement model and structural model.

\subsection{Data collection}

This study obtains an email list from a private seller. This seller provided a list including about 1500 small and medium enterprises providing the logistics and supply chain industry services in Vietnam. The data collection is about two months in length. First, after the obtaining of the list, an email was sent to these enterprises. While ago, a friendly reminder was sent to 
improve the response rate. After two months, there were 175 filled surveys. It is noted that 175 observations were used to analyze. The response rate is about $11.67 \%$.

\subsection{Variables measures}

All instruments used to measure variables were adopted from prior studies. Due to the original instruments being written in English, a translating process was established to meet the demand of Vietnamese respondents. During the translation process, this study is beneficial from a manager who has experience in the logistics and supply chain industry. As a result, there is some minor revision on the statement items of these instruments. The item statement asks the target respondents to rate their agreement based on a five-point Likert scale, which is the range of " 1 " (totally disagree) to " 5 " (totally agree). This study relies on the instrument from (Ma \& Cha, 2012) to measure the degree of CAC_ENV_REG (Ma \& Cha, 2012)(Ma \& Cha, 2012)(Ma \& Cha, 2012)(Ma \& Cha, 2012)(Ma \& Cha, 2012)(Ma \& Cha, 2012)(Ma \& Cha, 2012)(Ma \& Cha, 2012)(Ma \& Cha, 2012)(Ma \& Cha, 2012). There are five items in this instrument. This instrument was previously used in the context of an emerging country (see Zhang et al., 2018), and as such, it is suitable for the research context. Instead of considering each type of ES, this study adopts the ES instrument from Banerjee (2002). It is similar to the study of (Kraus et al., 2020). One reason is that this author argued that ES might differ in degree based on the focus on environmental issues of the organizations. As a result, this concept allows the capture of the degree to which environmental issues are integrated into the strategic planning process. It is adequate because, as argued earlier, ES is varied in degree (Lee \& Rhee, 2007). This instrument is a second-order construct consisting of two dimensions: environmental corporate strategy (ENV_CORP_STG) and environmental business strategy (ENV_BUS_STG). There are five items in the first dimension and three items in the second dimension. To measure the degree of EP, this study relies on the instrument of (Zhu \& Sarkis, 2004). In this instrument, there are six items. This instrument has high reliability because Laguir et al. (2020) used it to measure the EP of 3PLSPs.

\subsection{Common method bias}

An assessment of common method bias is required due to data collected from the same survey. Thus, Harman's single factor test was performed. The results show that $40.88 \%$ is accounted for total variances. Ihis value is below the threshold value of $50 \%$ (Podsakoff \& Organ, 1986). In this regard, there is no factor accounting for the majority of the variances. Thus, it is possible to analyze further.

\section{Results}

\subsection{Measurement model}

Table 1

$\underline{\text { Indicators' loadings and reliability, convergent, and discriminant validity test }}$

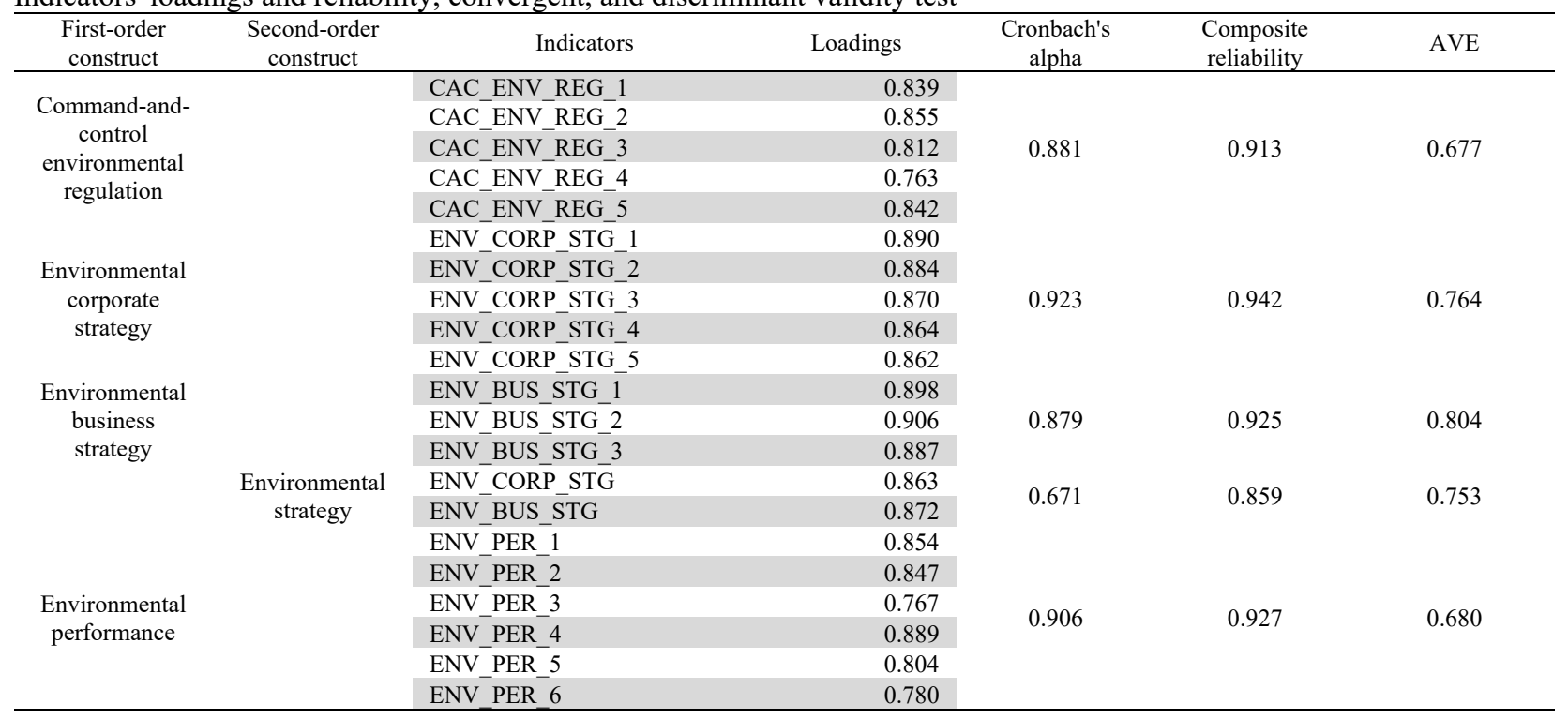

According to Table 1 and Table 2, both first-order and second-order latent variables used in this study are subjective to the requirement of indicator loadings and the tests of reliability, convergent, and discriminant validity. Particularly, the requirement of indicator loadings is that the loadings of the items are higher than the threshold value of 0.708 (Hair, Risher, Sarstedt, \& Ringle, 2019). Reliability tests were assessed by using critical ratio and Cronbach's Alpha. The critical ratio is 
necessarily above the threshold value of 0.7 (Hair et al., 2019), and Cronbach's Alpha is necessarily higher than 0.6 (Sharma, 1996). Convergent validity is met if average variance extracted (AVE) was above the threshold value of 0.50 (Hair et al., 2019). The establishment of discriminate validity requires the Heterotrait-Monotrait (HTMT) ratio of correlations between constructs to be lower than the threshold value of 0.85 (Henseler, Ringle, \& Sarstedt, 2015). It is noted that, there is no evaluation of the HTMT ratio between ENV_STG and ENV_BUS_STG, ENV_CORP_STG respectively because these variables are the first-order constructs of ENV_STG.

Table 2

Heterotrait-Monotrait ratio

\begin{tabular}{lccc}
\hline & CAC_ENV_REG & ENV_BUS_STG & ENV_CORP_STG \\
\hline CAC_ENV_REG & & & ENV_PER \\
ENV_BUS_STG & 0.444 & 0.558 & \\
ENV_CORP_STG & 0.441 & 0.454 & 0.404 \\
ENV_PER & 0.216 & - & - \\
ENV_STG & 0.596 & 0.574 \\
\hline
\end{tabular}

\subsection{Structural model}

In partial least squares, the assessment of the structural model requires the assessment of the collinearity (VIF), the model's explanatory power $\left(R^{2}\right)$, and predictive accuracy (Stone-Geisser $Q^{2}$ ). To do this, first of all, this study performs the bootstrapping procedure of 5.000 replacements to assess the structural model. Next, the required criteria of VIF, $R^{2}$, and $Q^{2}$ were examined. VIF above 3 indicates the absence of collinearity (Hair et al., 2019). $R^{2}$ above the 0.25 establishes the model's explanatory power (Hair et al., 2019). $Q^{2}$ value above zero demonstrates the predictive accuracy of the research model (Hair et al., 2019). Table 3 shows that all the required criteria are met.

Table 3

$R^{2}, Q^{2}$, and VIFs

\begin{tabular}{|c|c|c|c|c|c|}
\hline & \multirow{2}{*}{$R^{2}$} & \multirow{2}{*}{$Q^{2}$} & \multicolumn{3}{|c|}{ VIFs } \\
\hline & & & CAC ENV REG & ENV PER & ENV STG \\
\hline $\begin{array}{l}\text { CAC ENV REG } \\
\end{array}$ & & & & 1.271 & 1.000 \\
\hline ENV PER & 0.210 & & & & \\
\hline ENV STG & 0.213 & & & 1.271 & \\
\hline
\end{tabular}

Table 4 shows that the last three hypotheses are significant while the first hypothesis is not. Particularly, the relationship between CAC ENV REG and EP is insignificant $(\beta=-0.014, p=0.856)$. Next, the relationship between CAC ENV REG and $\mathrm{ES}$ is positive $(\beta=0.462, p<0.0001)$. Also, it is observed that the relationship between $\mathrm{ES}$ and $\mathrm{EP}$ is positive $(\beta=0.465$, $p<0.001)$.

Table 4

Research results

\begin{tabular}{llrrr}
\hline Hypothesis & Path & Beta & $t$-value & $p$-values \\
\hline H1 & CAC_ENV_REG $\rightarrow$ ENV_PER & -0.014 & 0.181 & 0.856 \\
H2 & CAC_ENV_REG $\rightarrow$ ENV_STG & 0.462 & 7.380 & 0.000 \\
H3 & ENV_STG $\rightarrow$ ENV_PER & 0.465 & 6.322 & 0.000 \\
H4 & CAC_ENV_REG $\rightarrow$ ENV_STG $\rightarrow$ ENV_PER & 0.215 & 4.854 & 0.000 \\
\hline
\end{tabular}

The last hypothesis requires the mediating assessment. This assessment follows the procedure of Zhao, Lynch Jr, \& Chen (2010). Due to the insignificant relationship between dependent and independent variables and the significant relationship between these two variables and the mediator, the mediating effects of ES on the link between CAC ENV REG and EP is significant $(\beta=0.215, p<0.001)$. Furthermore, the confidence interval of this mediating effect is between 0.136 and 0.307 . Thus, ES fully mediates the link between CAC ENV REG and EP.

\section{Discussions}

\subsection{Theoretical implications}

First, the results show that CAC ENV REG has a positive association with ES. In this regard, this finding refers to the fact that 3PLSPs pursue ES due to CA $\bar{A}$ ENV REG. A regulation as CAC ENV REG includes the compulsory laws, rules, and policies established to protect the natural environment (López-Gamero et al., 2009). As a result, 3PLSPs must comply with this regulation to avoid the legal risk (e.g., close monitoring of government entities) and legal coercion (e.g., tighter enforcement of current regulations) (Berrone et al., 2013). This explanation is consistent with institutional theory. According to this theory, a regulation established by the government can refer to a coercive pressure aiming to reinforce 3PLSPs to comply with (see Powell \& DiMaggio, 2012). A consequence of this reinforcement is that 3PLSPs pursue the ES. This finding shares the similarity with Peng, Tu, Elahi, and Wei (2018), who found that CAC_ENV_REG induces high-pollution 
enterprises in China to pursue the ES. Second, the results indicate a positive association between ES and EP. It can be interpreted that 3PLSPs pursuing ES can find the implications of EP. The following explanation provides insight into this relationship. Particularly, the settings of environmental goals and objectives allow the enhancement of EP (see Eagan \& Joeres, 1997). These settings can be found when the ES is formed. When pursuing an ES, the ultimate goal of this strategy is to gain the environmental goals and objectives. It results in the implications of EP by reducing the harmful impact of the current operational activities on the natural environment (see Jaeckel, 2020). In this regard, 3PLSPs can improve EP thanks to the pursuit of ES. This finding is consistent with prior studies' results, which indicate the positive relationship between ES and EP (see Kraus et al., 2020; Latan et al., 2018; Solovida \& Latan, 2017). Third, the results show the full mediating effect of ES on the link between CAC_ENV_REG and EP. In this regard, 3PLSPs can enhance EP by pursuing ES when there is a CAC_ENV_REG. This finding can be interpreted through the theoretical lens of contingency theory. According to this theory, organizations can find performance implications thanks to aligning the external environment and their strategic pursuit. In this regard, 3PLSPs need to pursue an ES to enhance EP when CAC_ENV_REG is implemented. This finding also suggests that the impact of environmental regulation on EP is indirect. In this regard, this finding is consistent with prior studies' results demonstrating there are mediators between this relationship (see Graafland \& Bovenberg, 2020; Guerci et al., 2016; Jin et al., 2019; Wu et al., 2020).

\subsection{Practical implications}

This study also provides practical implications, which can be helpful for practitioners who show an interest in the environmentally friendly operation of 3PLSPs. Particularly, from the government's perspective, environmental regulation may impact the EP of 3PLSPs. This finding reveals that 3PLSPs passively react to the regulation to improve their EP. However, that perspective does not provide insight into how these providers can actively improve EP. The mediating finding may reflect this. This finding indicates that the alignment between ES and environmental regulation allows the enhancement of EP. In this regard, 3PLSPs can actively react to implementing CAC_ENV_REG to improve EP by pursuing the ES. This finding is crucial because it emphasizes the active role of 3PLSPs in dealing with CAC_ENV_REG.

\section{Conclusions, practical implications, and limitations}

This study's purpose is to shed light on how the CAC_ENV_REG has a positive impact on EP through the pursuit of ES. From the theoretical lens of contingency theory and institutional theory, this study examines the mediating effects of ES. Data was collected by using the survey method. 175 3PLSPs are participating in this study. PLS-SEM was used to analyze data. The results suggest the ES plays a mediating impact on the link between CAC_ENV_REG and EP. This study is subject to three following limitations. First, due to the original instrument written in English, a translating process was performed. Although there is assistance from a person having experience in the industry, the translated questionnaire may not reflect the original ones, which creates noise on the results. Second, because this study uses an email list purchased from a private seller, it may create a barrier to establish trust with the target respondents. As a result, it may be a cause of the low response rate. Third, this study collects data in Vietnam, and thus, the generalization of this study's results to other countries may be problematic. Despite these mentioned limitations, there are several avenues for the future research based on this study's results. First, it is crucial to extend this study by adding another type of environmental regulation as market-based environmental regulation. In this regard, that study can answer whether or not market-based environmental regulation influences ES, and the alignment between these two allows EP implications. Second, future research can focus on internal factors rather than external factors as environmental regulation. In this regard, those studies can shed light on whether or not EP can be rooted in the internal aspects of organizations.

\section{References}

Banerjee, S. B. (2002). Corporate environmentalism: The construct and its measurement. Journal of Business Research, 55(3), 177-191.

Bansal, P., \& Roth, K. (2000). Why companies go green: A model of ecological responsiveness. Academy of Management Journal, 43(4), 717-736.

Berrone, P., Fosfuri, A., Gelabert, L., \& Gomez-Mejia, L. R. (2013). Necessity as the mother of 'green'inventions: Institutional pressures and environmental innovations. Strategic Management Journal, 34(8), 891-909.

Delmas, M., Hoffmann, V. H., \& Kuss, M. (2011). Under the tip of the iceberg: Absorptive capacity, environmental strategy, and competitive advantage. Business \& Society, 50(1), 116-154.

DiMaggio, P. J., \& Powell, W. W. (1983). The iron cage revisited: Institutional isomorphism and collective rationality in organizational fields. American Sociological Review, 48(2), 147-160.

Do, B., Nguyen, U., Nguyen, N., \& Johnson, L. W. (2019). Exploring the proactivity levels and drivers of environmental strategies adopted by vietnamese seafood export processing firms: A qualitative approach. Sustainability, 11(14), 3964.

Eagan, P. D., \& Joeres, E. (1997). Development of a facility-based environmental performance indicator related to sustainable development. Journal of Cleaner Production, 5(4), 269-278.

Eiadat, Y., Kelly, A., Roche, F., \& Eyadat, H. (2008). Green and competitive? An empirical test of the mediating role of environmental innovation strategy. Journal of World Business, 43(2), 131-145. 
Eisenhardt, K. M., \& Martin, J. A. (2000). Dynamic capabilities: what are they? Strategic Management Journal, 21(10-11), 1105-1121.

Evangelista, P., Santoro, L., \& Thomas, A. (2018). Environmental sustainability in third-party logistics service providers: A systematic literature review from 2000-2016. Sustainability, 10(5), 1627.

Graafland, J., \& Bovenberg, L. (2020). Government regulation, business leaders' motivations and environmental performance of SMEs. Journal of Environmental Planning and Management, 63(8), 1335-1355.

Guerci, M., Longoni, A., \& Luzzini, D. (2016). Translating stakeholder pressures into environmental performance-the mediating role of green HRM practices. The International Journal of Human Resource Management, 27(2), $262-289$.

Hair, J. F., Risher, J. J., Sarstedt, M., \& Ringle, C. M. (2019). When to use and how to report the results of PLS-SEM. European Business Review, 31(1), 2-24.

Henriques, I., \& Sadorsky, P. (1996). The determinants of an environmentally responsive firm: An empirical approach. Journal of Environmental Economics and Management, 30(3), 381-395.

Henseler, J., Ringle, C. M., \& Sarstedt, M. (2015). A new criterion for assessing discriminant validity in variance-based structural equation modeling. Journal of the Academy of Marketing Science, 43(1), 115-135.

Jaeckel, A. (2020). Strategic environmental planning for deep seabed mining in the area. Marine Policy, 114, 103423.

Jin, J., Du, J., Long, X., \& Boamah, K. B. (2019). Positive mechanism of foreign direct investment enterprises on China's environment: Analysis of host country regulation and parent company management. Journal of Cleaner Production, 227, 207-217.

Kim, K. (2018). Proactive versus reactive corporate environmental practices and environmental performance. Sustainability, 10(1), 97.

Kong, D., Yang, X., Liu, C., \& Yang, W. (2020). Business strategy and firm efforts on environmental protection: Evidence from China. Business Strategy and the Environment, 29(2), 445-464.

Kraus, S., Rehman, S. U., \& García, F. J. S. (2020). Corporate social responsibility and environmental performance: The mediating role of environmental strategy and green innovation. Technological Forecasting and Social Change, 160, 120262.

Laguir, I., Stekelorum, R., \& El Baz, J. (2020). Going green? Investigating the relationships between proactive environmental strategy, GSCM practices and performances of third-party logistics providers (TPLs). Production Planning \& Control, 114.

Latan, H., Jabbour, C. J. C., de Sousa Jabbour, A. B. L., Wamba, S. F., \& Shahbaz, M. (2018). Effects of environmental strategy, environmental uncertainty and top management's commitment on corporate environmental performance: The role of environmental management accounting. Journal of Cleaner Production, 180, 297-306.

Lee, S. Y., \& Rhee, S. K. (2007). The change in corporate environmental strategies: a longitudinal empirical study. Management Decision.

Li, R., \& Ramanathan, R. (2018). Exploring the relationships between different types of environmental regulations and environmental performance: Evidence from China. Journal of Cleaner Production, 196, 1329-1340.

Liao, Y. C., \& Tsai, K. H. (2019). Innovation intensity, creativity enhancement, and eco-innovation strategy: T he roles of customer demand and environmental regulation. Business Strategy and the Environment, 28(2), 316-326.

López-Gamero, M. D., Molina-Azorín, J. F., \& Claver-Cortés, E. (2009). The whole relationship between environmental variables and firm performance: Competitive advantage and firm resources as mediator variables. Journal of Environmental Management, 90(10), 3110-3121.

Ma, F., \& Cha, N. (2012). The Impact of Environmental Regulation on Technological Innovation Performance-The Moderating Role of Institutional Environment. R\&D Management, 24(1), 60-66.

Meyer, J. W., \& Rowan, B. (1977). Institutionalized organizations: Formal structure as myth and ceremony. American journal of Sociology, 83(2), 340-363.

Meyer, J. W., Rowan, B., Powell, W. W., \& DiMaggio, P. J. (1991). The new institutionalism in organizational analysis. The new institutionalism in organizational analysis, 41-62.

Ngo, Q.-H. (2020). Effectiveness of Management Accounting System in Public Healthcare Sector: An Empirical Investigation in Vietnam. Asian Journal of Business and Accounting, 13(2), 147-180.

Ngo, Q.-H. (2021a). How market orientation induces small businesses' performance: The role of strategic fits. Gadjah Mada International Journal of Business, 23(1), 55-75.

Ngo, Q.-H. (2021b). The impact of market orientation on small businesses' performance in Vietnam: The mediating effects of the management accounting system. Entrepreneurial Business and Economics Review, 9(3), 59-72.

Ngo, Q.-H. (2021c). The impact of prospecting strategy on small business performance in Vietnam: the role of broad-scope management accounting system. Strategic Management-International Journal of Strategic Management and Decision Support Systems in Strategic Management, 26(2).

Peng, B., Tu, Y., Elahi, E., \& Wei, G. (2018). Extended Producer Responsibility and corporate performance: Effects of environmental regulation and environmental strategy. Journal of Environmental Management, 218, 181-189.

Podsakoff, P. M., \& Organ, D. W. (1986). Self-reports in organizational research: Problems and prospects. Journal of Management, 12(4), 531-544.

Porter, M. E., \& Van der Linde, C. (1995). Toward a new conception of the environment-competitiveness relationship. Journal of Economic Perspectives, 9(4), 97-118.

Powell, W. W., \& DiMaggio, P. J. (2012). The new institutionalism in organizational analysis: University of Chicago press. 
Requate, T. (2005). Dynamic incentives by environmental policy instruments - a survey. Ecological Economics, 54(2-3), 175-195.

Roome, N. (1992). Developing environmental management strategies. Business Strategy and the Environment, 1(1), 11-24.

Rugman, A. M., \& Verbeke, A. (1998). Corporate strategies and environmental regulations: An organizing framework. Strategic Management Journal, 19(4), 363-375.

Scott, W. R. (2013). Institutions and organizations: Ideas, interests, and identities: Sage publications.

Sharma, S. (1996). Applied multivariate techniques. New York, NY, United States: Wiley.

Solovida, G. T., \& Latan, H. (2017). Linking environmental strategy to environmental performance. Sustainability Accounting, Management and Policy Journal, 8(5), 595-619.

Venkatraman, N., \& Prescott, J. E. (1990). Environment-strategy coalignment: An empirical test of its performance implications. Strategic Management Journal, 11(1), 1-23.

Wang, Z., Zhang, B., \& Zeng, H. (2016). The effect of environmental regulation on external trade: empirical evidences from Chinese economy. Journal of Cleaner Production, 114, 55-61.

Wu, J., Yang, J., \& Zhou, Z. (2020). How does environmental regulation affect environmental performance? A case study of China's regional energy efficiency. Expert Systems, 37(3), e12326.

$\mathrm{Yu}$, W., Ramanathan, R., \& Nath, P. (2017). Environmental pressures and performance: An analysis of the roles of environmental innovation strategy and marketing capability. Technological Forecasting and Social Change, 117, 160169.

Zhang, Y., Wang, J., Xue, Y., \& Yang, J. (2018). Impact of environmental regulations on green technological innovative behavior: An empirical study in China. Journal of Cleaner Production, 188, 763-773.

Zhao, X., Lynch Jr, J. G., \& Chen, Q. (2010). Reconsidering Baron and Kenny: Myths and truths about mediation analysis. Journal of Consumer Research, 37(2), 197-206.

Zhou, Y., Shu, C., Jiang, W., \& Gao, S. (2019). Green management, firm innovations, and environmental turbulence. Business Strategy and the Environment, 28(4), 567-581.

Zhu, Q., \& Sarkis, J. (2004). Relationships between operational practices and performance among early adopters of green supply chain management practices in Chinese manufacturing enterprises. Journal of Operations Management, 22(3), 265-289. 
(C) 2021 by the authors; licensee Growing Science, Canada. This is an open access article distributed under the terms and conditions of the Creative Commons Attribution (CCBY) license (http://creativecommons.org/licenses/by/4.0/). 